\title{
The Influence of Gender, Intellectual Ability, Academic Self-Concept, Self-Regulation, Learning Strategies, Popularity and Parent Involvement in Early Adolescence
}

\author{
Alejandro Veas, Raquel Gilar, and Pablo Miñano
}

\begin{abstract}
The present study examined the predictive effects of gender, intellectual ability, self-concept, motivation, learning strategies, popularity and parent involvement on academic achievement. Hiearchical regression analysis were performed with six steps in which each variable was included, among a sample of 1398 high school students (mean age $=12.5$; standard deviation $=.67$ ) of eight education centers from the province of Alicante (Spain). The results revealed significant predictive effects of all of the variables, explaining $59.1 \%$ of the total variance.
\end{abstract}

Index Terms-Academic achievement, cognitive variables, motivational variables, contextual variables.

\section{INTRODUCTION}

Academic achievement is one of the most studied construct in the educational psychology field, and an important number of variables have been considered as real predictors [1]-[3]. The analysis of the interaction of these components through different statistical methods has been taken into account in educational research to understand how cognitive and motivational factors influence academic achievement [4], [5]. However, there are few studies in which cognitive and motivational variables are included with contextual variables, such as popularity or parent involvement, in the same predicting model. In the present study, a hierarchical regression analysis is presented. Based on the main theoretical contributions, we analyze the predictive effects of gender, intellectual ability, self-concept, motivation, learning strategies, popularity and parent involvement on academic achievement.

\section{A. Gender and Academic Achievement}

During the last decades, the large number of studies about the relationship between gender and academic achievement has highlighted diverse results. There is a common thought that "the trend of male underachievement has been evident for at least the last decade" [6], as well as girls typically get lower results in science areas (mathematics, engineering and technology). However, other variables related such as socio-economical level or disadvantaged backgrounds clearly affect this relationship and increase these differences. In this

Manuscript received December 2, 2014; revised February 27, 2015. This work was supported in part by the Vice Chancellor of Research of the University of Alicante under Grant GRE 11-15, and by the Spanish Ministry of Economy and Competitiveness under Grant EDU2012-32156.

The authors are with the Department of Developmental Psychology and Didactics, Faculty of Education, University of Alicante, Spain (e-mail: Alejandro.veas@ua.es, Raquel.gilar@ua.es, Pablo.m@ua.es). sense, there have been stereotypical views of gender related abilities which contribute to this disparity. Nevertheless, literature review have pointed out this tendency, like Hyde \& Linn [7], who concluded in a meta-analysis that there were more similarities than differences between boys and girls, even in those areas where typical gaps have been detected, like mathematics or science. These advances allow overcoming classical theories, focusing on more objective outcomes about the performance trends of boys and girls.

\section{B. Intellectual Ability and Academic Achievement}

Intellectual ability is the most studied cognitive variable to predict academic achievement, showing a clear direct impact [8], although with some variability [9]. To understand the extent of motivational variables on the prediction of academic achievement, Gagné and St. Père [10] assessed the contribution of intrinsic, extrinsic and persistence motivation to academic achievement after controlling the predictive power of intelligence in a sample of 200 female high school students. They confirm that cognitive ability is the best predictor of school achievement but also a lack of correlation between intellectual ability and motivation. It is important to discriminate the level of prediction of motivational variables beyond intellectual ability.

\section{Self-Concept and Academic Achievement}

Among the motivational variables, self-concept has been considered as one of the major constructs by the scientific community [11]-[15]. Self-concept is usually defined as a set of perceptions of personal behaviors in concrete situations through inferences about the self in different domains [16] The multidimensional approach of self-concept is a key to its consideration as one of the most important motivational theories of the last 30 years [17]. In the educational field, academic self-concept and academic achievement are often highly correlated, even more so than other self-concept or self-esteem domains [18]. Huang [19], in a recent meta-analysis, confirmed medium to longitudinal relations between self-concept and academic achievement, as have additional previous long-terms studies [20].

\section{Self-Regulation and Academic Achievement}

According to previous studies, self-concept is closely related to other motivational and cognitive variables [21], [22], and for this reason, they have been included in all recent models of academic achievement. In relation to students 'ability to self-regulate their own process, it is clear that constitutes a key element in explaining academic success [23], [24]. Self-regulation refers to students'" self-generated 
thoughts, feelings, and actions which are systematically oriented toward the attainment of goals" [25], and the use of internalized self-regulatory strategies help individuals to achieve in school [26]. Students are self-regulated to the degree that they are meta-cognitively, motivationally and behaviorally active participants in their learning process [27].

\section{E. Learning Strategies and Academic Achievement}

One of the main cognitive variables that is influenced by motivational variables is learning strategies [28], [29]. A subject who is actively applying learning processes is normally considered as self-competent, using meta-cognitive strategies, which include self-regulating learning [30] and turning the academic content into significant content while being responsible about his/her learning objectives. Therefore and adequate use of learning strategies has been positively related to higher academic achievement [5]. Learning strategies can also be used for enhancing self-image, which implies motivational, affective and cognitive consequences, but it can provoke negative academic achievement [31]. For example, whether a student perceives concrete tasks as a threat to his/her self-concept, a possible solution would be the avoidance of effort during these tasks. Due to these consequences, positive self-concept and self-regulation are necessary to obtain optimal learning strategies focused on significant content.

\section{F. Popularity and Academic Achievement}

Significant relations have been established between popularity and academic achievement [32]-[34]. Some indicators have been used to examine these behaviors better, such as peer acceptance, friendships or popular status. While the first two indicators try to evaluate the quality or the level in which a child is socially accepted, the last refers to the relative prestige within the peer group and could be associated with prosocial behaviors but also with aggressive or dominant behaviors, which can negatively affect academic achievement [35].

\section{G. Parent Involvement and Academic Achievement}

The last construct included in our model is parent involvement. We ca $n$ define it as a set of parent behaviors in the home and school that support their children's educational progress [36]. Multiple authors indicate its significant contribution to academic achievement [37], [38]. However, its statistical impact has been widely discussed, as some researchers indicate that good parental practices do not predict better academic performance [39]. More quantitative contributions are needed to clarify the level of influence of parent involvement on student achievement.

\section{H. Research Hypothesis}

Academic achievement gives, in general terms, a great value to adolescent-aged students, so that the identification and study of personal, motivational and contextual predictors are crucial to improve school practices. Given the theoretical and empirical impact of the constructs described above, we hypothesized that each of the variables included, that is, gender, intellectual ability, self-concept, motivation, learning strategies, popularity and parent involvement, have an important independent predictive power on academic achievement.

\section{MATERIALS AND METHODS}

\section{A. Participants}

A total of 1456 students from the first and second academic years of compulsory secondary education took part in this study. Of these, 58 students were excluded due to errors or omissions in their answers or because they did not have sufficient command of Spanish. A total of 1398 subjects $(n=1398)$ were included in the analysis: $53 \%$ of the students were male and $47 \%$ were female, with a mean age of 12.5 years and a standard deviation of .67. Conglomerate sampling was employed using the group-class as the sampling unit. A total of eight educative centers from the province of Alicante (Spain) were included in which there were two private schools and six state schools. The majority of participants (1137, $81.4 \%$ ) studied at a state school, whereas $261(18.6 \%)$ studied at a private school. The course split was such that $52.4 \%$ were in their first year and $47.6 \%$ were in their second year.

\section{B. Measures}

Measures of intelligence, self-concept, goal orientations, learning strategies, popularity and parent involvement were collected during the second quarter of the academic year 2011-2012.

To measure intellectual ability, we utilized scale 2 of the Factor G test by Cattell \& Cattell [40], adapted into Spanish by TEA Editions. This collectively applied scale consists of four subtests: series, classification, matrices and conditions, which produce an intelligence quotient (IQ) that measures fluid general intelligence. The reliability, obtained by the two-half method and corrected by the Spearman-Brown formula, was .78 in first-year participants and .69 in second-year participants

To evaluate self-concept, we used the ESEA-2 [Self-concept evaluation scale for adolescents] elaborated by González-Pienda and collaborators [41]. This questionnaire is a Spanish adaptation of the SDQ-II [Self-Description Questionnaire] by Marsh [42], validated in a study with 503 students in compulsory secondary education. It is composed of 70 items measuring 11 specific self-concept dimensions, to which students must answer on a Likert scale from 1 to 6 depending on the extent to which they agree or disagree with each statement. In the authors evaluation work, all obtained Cronbach's alpha values were between .73 and .91. For this study, we only selected verbal, math and academic self-concept factors, with Cronbach's alpha values of .84, .90 and .75 , respectively.

We evaluate self-regulation through the scale Motivation/self-regulation of the School Attitude Assessment Survey-Revised (SAAS-R) developed by McCoach and Siegle [43], composed by 10 questions, using a seven-point Likert-type agreement scale. Previous validations showed acceptable reliability with and internal consistency for each scale above .85 . In addition, several studies have analyzed criterion-related validity, confirming the relation between attitudes measured by the SAAS-R and students'academic achievement [44], [45]. 
To measure learning strategies, we used the CEA [Learning Strategies Questionnaire], produced by Beltrán, Pérez, and Ortega [46]. The test evaluates four large scales taking into account different strategies, namely awareness, development, personalization and metacognition, from which only the development, personalization and meta-cognitive scales were used in this study. To obtain the scores for these three scales, students answered a total of 50 items indicating the extent to which each formulated strategy was true on a Likert scale from 1 to 5, and we obtained sample Cronbach's alpha values of $.87, .77$ and .77 for the three scales, respectively.

The variable popularity was evaluated with the BULL-S as elaborated by Cerezo [47]. It is a computerized instrument correction that detects abuse and violent situations among students, as well as different coexisting profiles: acceptation, rejection, victimization and isolation. The test follows the methodological line of sociometry using the peer nomination technique and analyzes the internal structure of the classroom. It is composed of 15 items, although we have only used the first four items related to sociometric questions. The test has two versions: P for parents and A for students. We only used version $\mathrm{A}$, and an index of peer acceptation named popularity was extracted for the purpose of this study.

Parent involvement was measured by the CIF [Parent Involvement Questionnaire], which was elaborated by our research group. This questionnaire is aimed at students who value the perception of involvement of their parents in the educational process, their monitoring and the level of importance of the educational process to themselves. The instrument is structured as 20 items that evaluate 4 factors: perception of support, organization and interest in the educational process; expectations (professional future); and the center relationship and time of support with homework. Students must answer on a Likert scale from 1 to 5 depending on the frequency they do each statement $(1=$ never or hardly ever; 5 = always or mostly). An example of an item is: " $M y$ parents help me organize my homework”. In our study, we obtained Cronbach's alpha values of .70 for the first factor; .65 for the second, .65 for the third and .71 for the last factor.

School grades were used as an indicator of academic achievement. Teachers provided full-term grades from nine subjects, and the average grades were calculated on continuous scales ranging from 0 to 10 . The scores of the subjects of each course present a high reliability, with Cronbach's alpha values of .93 for the first course participants and .94 for the second course participants.

\section{Procedures}

The data were obtained in the classroom and during school hours. The subjects participated voluntarily and with the informed consent of their parents or legal guardians, with the guarantee of confidentiality.

The tests were run in the various schools by several specialist collaborators who received prior general training on how to apply the various instruments. The study was conducted during the academic year 2011-2012, from November to March, over four sessions that each lasted an hour.

\section{Data Analysis}

We used a predictive correlational study design in which hierarchical regression procedures were performed as a technical analysis with the SPSS software package version 21.0. Academic achievement was used as criteria, and six steps were included to understand whether intellectual ability, self-concept, goal orientation, learning strategies, popularity and parent involvement have a significant contribution to explaining the variance, beyond the contributions of the other variables.

\section{RESULTS}

Table I presents the descriptive analyses of each variable and the correlation matrix between all of the dimensions of the variables of interest. Positive and significant correlations have been found among some of the dimensions. We can also report some negative and significant correlations between time of support with homework and intellectual ability, academic self-concept and gender, respectively.

We conducted a hierarchical regression analysis (see Table II) in which gender was entered in the first step; followed by intellectual ability in the second step; academic self-concept in the third step; motivation/self-regulation in the fourth step; three dimensions of learning strategies in the fifth step (personalization, metacognition and elaboration scale); popularity in the sixth step; and four dimensions of parent involvement in the seventh step (time of support with homework, expectations, center relationship, perception of support, organization and interest in the educational process). Model 1 was significant $\left[R_{2}=.021, F_{(1,1396)}=29.346\right]$, and thus, being girl affects positively to academic achievement $[\beta$ $=.143, p<.001]$. In the second step (Model 2), intellectual ability predicted academic achievement beyond the effects of gender $\left[R_{2}=.464, F_{(2,1395)}=191.007, p<.001\right]$, and the change between models 1 and 2 was statistically significant $\left[R_{2}\right.$ change $=.194, \mathrm{~F}_{(3,1393)}=345.428$. In the third step (Model 3 ), we can appreciate that the contribution of academic self-concept was also statistically significant $[\beta=.555, p$ $<.001]$. The change between Models 3 and 2 was statistically significant $\left[R_{2}\right.$ change $\left.=.287, F_{(1,1394)}=805.369, p<.001\right]$. In the fourth step (Model 4), motivation / self-regulation significantly predicted academic achievement $[\beta=.122, p$ $<.001]$. The change between models 4 and 3 was significant $\left[R_{2}\right.$ change $\left.=.01, F_{(1,1393)}=29.835, p<.001\right]$. In the fifth step (Model 5), the elaboration and meta-cognition scale predicted positive academic achievement, whereas the personalization scale predicted negative academic achievement. The change between Models 5 and 4 was statistically significant $\left[R_{2}\right.$ change $\left.=.513, F_{(3,1390)}=19.784, p<.001\right]$. In the sixth step, we can appreciate that popularity has an important level of positive prediction $[\beta=.167, p<.001]$ with a significant increment of the model $\left[R 2\right.$ change $=.748, F_{(3,1390)}=19.784, p$ $<.001]$. In the seventh model (model 6), the predictions of the last three dimensions of parent involvement were positive and statistically significant, whereas the first dimension, time of support with homework, predicted negative academic achievement $[\beta=-.196, p<.001]$. This model explained $59.1 \%$ of the variance for the criteria $\left[R_{2}=.591, F_{(12,1385)}=\right.$ $166.77, p<.001]$. 
TABLE I: CORRELATION MATRIX BETWEEN VARIABLES AND DESCRIPTIVE STATISTICS

\begin{tabular}{|c|c|c|c|c|c|c|c|c|c|c|c|c|c|c|c|}
\hline & $\mathrm{M}$ & SD & 1 & 2 & 3 & 4 & 5 & 6 & 7 & 8 & 9 & 10 & 11 & 12 & 13 \\
\hline 1. & .47 & .50 & - & & & & & & & & & & & & \\
\hline 2. & $\begin{array}{l}107.0 \\
6\end{array}$ & 14.93 & .005 & - & & & & & & & & & & & \\
\hline 3. & 3.96 & .96 & .009 & $.274 b$ & - & & & & & & & & & & \\
\hline 4. & 51.17 & 11.37 & $.103 b$ & $.053 a$ & $.499 b$ & - & & & & & & & & & \\
\hline 5. & 70.93 & 13.71 & -.050 & $.086 \mathrm{~b}$ & $.342 b$ & $.495 b$ & - & & & & & & & & \\
\hline 6. & 37.38 & 6.56 & .010 & $.166 \mathrm{~b}$ & $.418 \mathrm{~b}$ & $.523 b$ & $.595 b$ & - & & & & & & & \\
\hline 8. & 5.89 & 4.09 & .036 & $.099 \mathrm{~b}$ & $.176 \mathrm{~b}$ & $.111 \mathrm{~b}$ & $.082 b$ & $.130 \mathrm{~b}$ & $.095 b$ & - & & & & & \\
\hline 9. & 16.04 & 4.78 & $-.111 b$ & $-.116 b$ & .044 & $.240 \mathrm{~b}$ & $.251 b$ & $.154 b$ & $.249 \mathrm{~b}$ & -.025 & - & & & & \\
\hline 10 & 20.87 & 3.70 & .021 & $.214 b$ & $.429 b$ & $.419 b$ & $.335 b$ & $.325 b$ & $.359 b$ & $.122 b$ & $.206 b$ & - & & & \\
\hline 11 & 18.95 & 3.88 & .031 & .041 & $.201 b$ & $.423 b$ & $.353 b$ & $.286 b$ & $.361 b$ & $.067 \mathrm{a}$ & $.487 b$ & $.386 b$ & - & & \\
\hline 12 & 21.03 & 3.31 & -.021 & $.103 b$ & $.275 b$ & $.351 b$ & $.224 b$ & $.283 b$ & $.279 b$ & $.084 b$ & $.443 b$ & $.449 b$ & $.409 \mathrm{~b}$ & - & \\
\hline
\end{tabular}

TABLE II: HIERARCHICAL REGRESSION ANALYSIS SUMMARY TABLE WITH ACADEMIC ACHIEVEMENT AS DEPENDENT VARIABLE

\begin{tabular}{|c|c|c|c|c|c|}
\hline Step and predictor variable & $\mathrm{B}$ & SE B & $\beta$ & $R_{2}$ & $\Delta R_{2}$ \\
\hline Step 1 & & & & .021 & - \\
\hline Gender & .511 & .094 & .143 & & \\
\hline Step 2 & & & & .464 & $.194 \mathrm{a}$ \\
\hline Intellectual ability & .053 & .003 & .441 & & \\
\hline Step 3 & & & & .709 & $.287 \mathrm{a}$ \\
\hline Academic self-concept & 1.02 & .036 & .555 & & \\
\hline Step 4 & & & & .716 & $.01 \mathrm{a}$ \\
\hline Motivation/self-regulation & .019 & .003 & .122 & & \\
\hline Step 5 & & & & .73 & $.02 \mathrm{a}$ \\
\hline Personalization scale & -.024 & .005 & -.188 & & \\
\hline Meta-cognition scale & .041 & .007 & .152 & & \\
\hline Elaboration scale & .013 & .006 & .083 & & \\
\hline Step 6 & & & & .748 & $.027 \mathrm{a}$ \\
\hline Popularity & .073 & .008 & .167 & & \\
\hline Step 7 & & & & .769 & $.031 \mathrm{a}$ \\
\hline Time of support with homework. & -.073 & .008 & -.196 & & \\
\hline Expectations. & .042 & .01 & .087 & & \\
\hline Center relationship & .025 & .01 & .055 & & \\
\hline Perception of support, organization and interest in educational process. & .037 & .012 & .069 & & \\
\hline
\end{tabular}

\section{DISCUSSION}

Few studies have analyzed the cognitive, motivational and contextual variables in a unique predictive model. The purpose of this study was to examine the significant contribution of the dimensions of gender, intellectual ability, academic self-concept, self-regulation, learning strategies, popularity and parent involvement on academic achievement.

According to our hypothesis, all of the steps included in the hierarchical regression analyses were statistically significant, so all of the variables make important contributions to the prediction of academic achievement.

This result demonstrates the importance of all types of constructs and specifically that beyond cognitive and motivational variables, popularity and parent involvement are equally essential indicators that affect academic achievement. Not only do teacher provide tools to enhance the performance of students, but parents and peers are also intervenient variables that could be seen as an opportunity or an obstacle to achieve better scholarly performance.

\section{A. Gender and Academic Achievement}

Results confirm previous studies where significant differences were in favor of females [48]. Girls appear to have established themselves as more reliable in terms of passing grades than their male peers. This situation begun by the mid-1990s, as boys began to emerge as significantly less successful than girls in terms of learning outcomes. There are many influences at this point: boys are more likely than girls to get referrals for behavioral issues, to drop out of school, to present reading problems, and to be identified with ADHD, among others.

\section{B. Intellectual Ability and Academic Achievement}

We confirm that intellectual ability is a strong predictor for academic achievement, similar to previous findings [49], [50]. However, we can see that its explained variance increased in the following models, so it seems particularly important to explain the specific contribution of the rest of the variables included.

\section{Academic Self-Concept and Academic Achievement}

One of the most important motivational variables is itself-concept, and its level of prediction was also satisfactory. Hence, academic self-concept implies different aspects of self-evaluation, which supports the multidimensional approach of the construct [51].

\section{Self-Regulation and Academic Achievement}


We can appreciate in the literature that this variables has a crucial direct influence on academic achievement, as our results have confirmed. Self-regulation is linked to motivation, which is the process whereby goal-directed activities are instigated and sustained [52], and we can observe indirectly its outcomes: selection of activities, effort, persistence, etc., monitoring their understanding and gauge their learning progress.

\section{E. Learning Strategies and Academic Achievement}

With regard to learning strategies, positive contributions have been made by meta-cognition and developmental strategies. The first plays a fundamental role in the selection and intelligent regulation of strategies and learning techniques, being classified as a general strategy, which can be applied to various domains [52]. The second integrates and relates new information with previous knowledge and requires a more sophisticated treatment because it focuses on the meaning rather than superficial aspects. In general terms, these affective and cognitive implications lead to better information retention. In the case of the personalization scale, which is related to creativity, critical thought and knowledge transference, we can expect high levels of negative prediction on academic achievement. High levels of creativity or the ability to classify information could not be related to significant content acquisition.

\section{F. Popularity and Academic Achievement}

A significant and positive prediction of academic achievement has been found with popularity, in line with previous results [53], [54]. In general terms, popular status leads to a feeling of belongingness in school, which increases good performance and motivation at school [55]. It is true that popular status could include students with bad behaviors, but the normal positive predictions identified by the results suggest that these groups are usually scarce.

\section{G. Parent Involvement and Academic Achievement}

This variable was included in the last step of our model, as it is the least studied in the educational field. As expected, we found that the three first dimensions included perception of support, organization and interest in the educational process; expectations and the center relationship were statistically and positively related to academic achievement, whereas time of support with homework was a predictor of negative academic achievement. Indeed, this last dimension is related to monitoring and checking, and various papers have noted the possible negative outcomes of monitoring, which can be related to authoritative and authoritarian parenting styles [56].

\section{CONCLUSION}

In summary, the present study indicates the importance of cognitive, motivation and contextual variables for a deeper comprehension of academic achievement in adolescents. We found that all of the variables included in each step of the hierarchical regression analysis were statistically significant and explained a considerable percentage of the variance. Furthermore, we need to give special relevance to contextual variables, specifically popularity and parent involvement, because of their fundamental influence on the academic achievement beyond motivational and cognitive variables, as it serves as a guide for educational practices.

\section{REFERENCES}

[1] J. L. Castejón and L. Navas, "Determinantes del rendimiento académico en la enseñanza secundaria: Un modelo causal (Determinants of academic achievement in secondary education: A causal model)," Análisis y Modificación de Conducta, vol. 18, no. 61, pp. 697-729, 1992.

[2] C. J. Inglés, M. C. Martínez-Monteagudo, J. M. García-Fernández, A. Valle, and J. L. Castejón, "Goal orientation profiles and self-concept of secondary school students," Revista de Psicodidáctica (Journal of Psychodidactics), 2014.

[3] A. Zuffianò, G. Alessandri, M. Gerbino, and B. P. Luengo, “Academic achievement: The unique contribution of self-efficacy beliefs in self-regulated learning beyond intelligence, personality traits, and self-steem," Learning and Individual Differences, vol. 23, pp. 158-162, 2013.

[4] J. Karbach, J. Gottschling, M. Spengler, K. Hegewald, and F. M Spinath, "Parental involvement and general cognitive ability as predictors of domain-specific academic achievement in early adolescence," Learning and Instruction, vol. 23, pp. 43-51, 2013.

[5] P. Miñano and J. L. Castejón, "Variables cognitivas y motivacionales en el rendimiento académico en lengua y matemáticas: Un modelo estructural," Revista de Psicodidáctica (Journal of Psychodidactics), vol. 16, no. 2, pp. 203-230, 2011.

[6] S. J. Gibb, D. Fergusson, and L. J. Hornwood, "Gender differences in educational achievement to age 25," Australian Journal of Education, vol. 52, no. 1, pp. 63-78, 2008

[7] J. S. Hyde and M. Linn, "Gender similarities in mathematics and science," Science, vol. 314, pp. 599-600, 2006.

[8] T. Chamorro-Premuzic and A. Furnham, "Self-assessed intelligence and academic performance," Educational Psychology, vol. 26, no. 6, pp. 769-779, 2006.

[9] J. L. Castejón, "Determinantes del rendimiento académico de los estudiantes y de los centros educativos: Modelos y factores," Determinants of Academic Achievement of Students and Schools, Alicante, Spain: Editorial Club Universitario, 1996

[10] F. Gagné and F. S. Père, "When IQ is controlled, does motivation still predict achievement?" Intelligence, vol. 30, no. 1, pp. 71-100, 2002.

[11] F. Guay, C. F. Ratelle, A. Roy, and D. Litalien, "Academic self-concept, autonomous academic motivation, and academic achievement: Mediating and addictive effects," Learning and Individual Differences, vol. 20, no. 6, pp. 644-653, 2010.

[12] H. W. Marsh and R. Shavelson, "Self-concept: Its multifaceted, hierarchical structure," Educational Psychologist, vol. 20, no, 3, pp. 107-123, 1985.

[13] H. W. Marsh, "A multidimensional, hierarchical model of self-concept: Theoretical and empirical justification," Educational Psychology Review, vol. 2, no. 2, pp. 77-172, 1990.

[14] W. W. Purkey, Self-Concept and School Achievement, Englewood Cliffs, NJ: Prentice-Hall, 1970.

[15] B. Weiner, "History of motivational research in education," Journal of Educational Psychology, vol. 82, pp. 616-622, 1990.

[16] H. W. Marsh and A. J. Martin, "Academic self-concept and academic achievement: Relations and causal ordering," British Journal of Educational Psychology, vol. 81, no. 1, pp. 59-77, 2011.

[17] B. Weiner, "History of motivational research in education," Journal of Educational Psychology, vol. 82, no. 4, pp. 616-622, 1990.

[18] J. Green et al., "Academic motivation, self-concept, engagement, and performance in high school: Key processes from longitudinal perspective," Journal of Adolescence, vol. 35, no. 5, pp. 1111-1122, 2012.

[19] C. Huang, "Self-concept and academic achievement: A meta-analysis of longitudinal relations," Journal of School Psychology, vol. 49, no. 5, pp. 505-528, 2011.

[20] H. W. Marsh, Self-Concept Theory, Measurement and Research into Practice: The Role of Self-Concept in Educational Psychology, Leicester, UK: British Psychological Society, 2007.

[21] S. Rodríguez, R. Cabanach, A. Valle, J. C. Núñez, and J. González, "Differences in the use of self-handicapping and defensive pessimism, and their relationships with achievement goals, self-steem and self-regulation strategies," Psicothema, vol. 16, pp. 625-631, 2004. 
[22] B. Spinath and J. Steinsmeier-Pelster, "Goal orientation and achievement: The role of ability self-concept and failure perception," Learning and Instruction, vol. 13, pp. 403-422, 2003.

[23] P. Fenollar, S. Román, and P. J. Cuestas, "University students' academic performance: An integrative conceptual framework and empirical analysis," British Journal of Educational Psychology, vol. 77, no. 4, pp. 873-891, 2007.

[24] C. A. Wolters, "The relation between high school students' motivational regulation and their use of learning strategies, effort, and classroom performance," Learning and Individual Differences, vol. 11 no. 3, pp. 281-299, 1999.

[25] B. J. Zimmerman, "Dimensions of academic self-regulation: A conceptual framework for education," in D. H. Schunk and B. J. Zimmerman, Eds., Self-Regulation of Learning and Performance: Issues and Educational Applications, Hillsdale, NJ: Lawrence Erlbaum Associates, pp. 3-21, 1994.

[26] D. B. McCoach, "A validation study of the school attitude assessment survey," Measurement and Evaluation in Counseling and Development, vol. 35, pp. 66-77, 2002.

[27] C. Mega, L. Ronconi, and R. D. Beni, "What makes a good student? How emotions, self-regulated learning, and motivation contribute to academic achievement," Journal of Educational Psychology, vol. 106 , no. 1 , pp. 121-131, 2014

[28] A. Kitsantas and B. J. Zimmerman, "College students' homework and academic achievement: The mediating role of self-regulatory beliefs," Metacognition and Learning, vol. 4, no. 2, pp. 97-119, 2009.

[29] J. S. Matthews, C. C. Pointz, and F. J. Morrison, "Early gender differences in self-regulation and academic achievement," Journal of Educational Psychology, vol. 101, no. 3, pp. 689-704, 2009.

[30] P. R. Pintrich, and E. V. D. Groot, "Motivational and self-regulated learning components of classroom academic performance," Journal of Educational Psychology, vol. 82, no. 1, pp. 33-40, 1990.

[31] J. A. González-Pienda and J. C. Núñez, "Personal determinants of learning and academic achievement," Instruction, Learning and Difficulties, Barcelona, Spain: Ediciones LU, 1997.

[32] M. Véronneau, F. Vitaro, M. Brendgen, T. J. Dishion, and R. E. "Tremblay, transactional analysis of the reciprocal links between peer experiences and academic achievement from middle childhood to early adolescence," Developmental Psychology, vol. 46, no. 4, pp. 773-790, 2010.

[33] K. R. Wentzel, "Relations between social competence and academic achievement in early adolescence," Child Development, vol. 62, no. 5, pp. 1066-1078, 1991.

[34] K. R. Wentzel, J. Elliot, and C. Dweck, "Peer relationships, motivation, and academic performance at school," in J. Elliot and C. Dweck, Eds., Handbook of Competence and Motivation, New York, USA: The Guildford Press, pp. 279-296, 2005.

[35] D. Schwartz, A. H. Gorman, J. Nakamoto, and T. McKay, "Popularity, social acceptance, and aggression in adolescent peer groups: Links with academic performance and school attendance," Developmental Psychology, vol. 42, no. 6, pp. 1116-1127, 2006.

[36] N. E. El Nokali, H. J. Bachman, and E. Votruba-Drzal, "Parent involvement and children's academic and social development in elementary school," Child Development, vol. 81, no. 3, pp. 988-1005, 2010.

[37] S. Phillipson and S. N. Phillipson, "Children's cognitive ability and their academic achievement: The mediation effects of parental expectations," Asia Pacific Education Review, vol. 13, no. 3, pp. 495-508, 2012

[38] M. A. Rogers, J. Theule, B. A. Ryan, G. R. Adams, and L. Keating, "Parental involvement and children's school achievement evidence for mediating processes," Canadian Journal of School Psychology, vol. 24, no. 1, pp. 34-57, 2009

[39] C. O. Opkala, A. O. Okpala, and F. E. Smith, "Parental involvement, instructional expenditures, family socioeconomic attributes, and student achievement," The Journal of Educational Research, vol. 95, no. 2, pp. 110-115, 2001

[40] R. Cattel, Test de Factor "g", Escala 2 (forma A) (Factor "g" Test, Scale 2), Institute for Personality and Ability Testing, Madrid, Spain: TEA Ediciones, 1994.

[41] J. A. González-Pienda, J. C. Núñez, S. González-Pumariega, L. Álvarez, C. Roces, and M. García, "A structural equation model of parental involvement, motivational aptitudinal characteristics, and academic achievement," The Journal of Experimental Education, vol 70, no. 3, pp. 257-287, 2002.

[42] H. W. Marsh, "A multidimensional, hierarchical model of self-concept: Theoretical and empirical justification," Educational Psychology Review, vol. 2, no. 2, pp. 77-172, 1990.
[43] D. B. McCoach and D. Siegle, "The school attitude assessment survey-revised: A new instrument to identify able students who underachieve," Educational and Psychological Measurement, vol. 63, pp. 414-429, 2003

[44] D. B. McCoach and D. Siegle, "A comparison of high achievers' and low achievers' attitudes, perceptions, and motivations," Academic Exchange Quarterly, vol. 5, pp. 71-76, 2001.

[45] D. B. McCoach and D. Siegle, "Factors that differentiate underachieving gifted students from high-achieving gifted students," Gifted Child Quarterly, vol. 47, pp. 144-154, 2003.

[46] J. Beltrán, L. Pérez, and M. Ortega, CEA. Cuestionario de Estrategias de Aprendizaje (CEA. Learning Stategies Questionnaire), Madrid, Spain: TEA Ediciones, 2006

[47] F. Cerezo, BULL-S. Test de Evaluación de la Agresividad Entre Escolares (BULL-S. Test for Assessing Aggressiveness among School Students), Manual de Referencia. Bizcaia, Spain: Grupo ALBOR-COHS, 2000.

[48] Eurydice. (2010). Gender differences in educational outcomes. European Commission. [Online]. Available: http://eacea.ec.europa.eu/education/eurydice/documents/thematic_rep orts/120EN.pdf.

[49] I. J. Deary, S. Strand, P. Smith, and C. Fernandes, "Intelligence and educational achievement," Intelligence, vol. 35 , no. 1, pp. 13-21, 2007.

[50] A. R. Jensen, The g Factor: The Science of Mental Ability, Westport, CT: Praeguer, 1998

[51] H. W. Marsh and R. Craven, "Academic self-concept: Beyond the dustbowl," in D. Phye and Gary, Ed., Handbook of Classroom Assessment: Learning, Achievement, and Adjustment. Educational Psychology Series, San Diego, USA: Academic Press, pp.131-198, 1997.

[52] D. H. Schunk, P. R. Pintrich, and J. L. Meece, Motivation in Education: Theory, Research, and Applications, 3rd ed., Upper Saddle River, NJ: Merrill/Prentice Hall, 2008.

[53] J. Nisbet and J. Shucksmith, Learning Strategies, Boston, MA: Routledge and Kegan Paul, 1986.

[54] L. H. Anderman, and T. M. Freeman, "Students' sense of belonging in school," Advances in Motivation and Achievement, vol. 13, pp. 27-63, 2004.

[55] E. Oberle and K. A. Schonert-Reichl, "Relations among peer acceptance, inhibitory control, and math achievement in early adolescence," Journal of Applied Developmental Psychology, vol. 34 no. 1 , pp. $45-51,2013$

[56] S. Areepattamannil, "Parenting practices, parenting style, and children's school achievement," Psychological Studies, vol. 55, no. 4, pp. 283-289, 2010

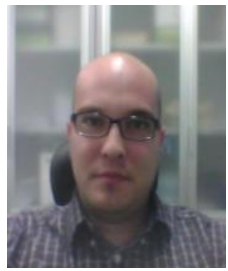

Alejandro Veas was born on June 27, 1987 in Murcia, Spain. He entered university in 2005 and received his bachelor degree in psychology from University of Murcia (UMU) in 2010, majored in clinical psychology. In 2011 he obtained a master of secondary education teacher in the same institution. $\mathrm{He}$ is currently a $\mathrm{PhD}$ student and research trainee in University of Alicante, Spain.

Mr. Veas previously worked as a teacher in two high schools and as a researcher assistant at the Meta-analysis Unit at the Department of Basic Psychology and Methodology and at the Department of Didactics and School Organization, University of Murcia. Mr. Veas is co-author of 3 papers and 4 communications congress, and has participated in 3 research projects. His research interests are focused on academic achievement, underachievement, high abilities, emotional intelligence and research methodology.

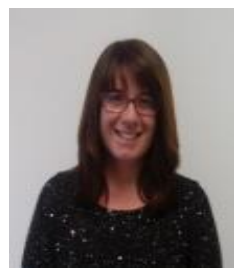

Raquel Gilar was born on September 18, 1974 in Alicante, Spain. In 2002 she obtained her $\mathrm{PhD}$ in educational psychology. She is a professor at the Department of Developmental Psychology and Didactics at University of Alicante, Spain, since 2003. She currently is the subdirector of the Department of Developmental Psychology and Didactics.

Dr. Gilar has managed and participated in numerous research projects, both national and international. Her research interests are focused on intelligence, underachievement, high abilities, emotional intelligence and teacher training. 


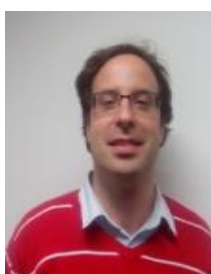

Pablo Minaño was born on January 31, 1979 in Alicante, Spain. In 2000 he obtained his bachelor degree in teacher education from the University of Alicante (UA), and started to work as a primary teacher at the school "La Inmaculada" in Alicante. In 2006, he obtained his bachelor at psycho-pedagogy at the same institution. Since 2008, he also work as an associate teacher at the Department of Developmental
Psychology and Didactics at the University of Alicante.

Dr. Miñano is the author of different research papers published in international journals. He has managed and participated in various research projects which have been granted by public administration. His research interests are focused on academic achievement, underachievement, academic motivation, intelligence and methodological research. 